\title{
Problem Kesehatan Reproduksi Perempuan Usia Subur Eks Pengungsi Timor Timur
}

\author{
Maria Lupita Nena Meo ${ }^{1}$ Maria Paula Marla Nahak ${ }^{2}$ \\ ${ }^{1}$ Prodi Ilmu Keperawatan, FK Universitas Sam Ratulangi \\ ${ }^{2}$ Prodi Ners, Universitas Citra Bangsa \\ Korespondensi: Email: lupita maria@ymail.com; marlanahak858@gmail.com
}

Submisi: 19 Juli 2019; Revisi: 21 April 2020; Penerimaan: 22 April 2020

\begin{abstract}
Background: The poverty issue affecting refugees, in principle, aggravates the reproductive health of refugee women.

Objective: This study aims to capture the reproductive health problems of the eligible women of the former East Timor refugees in 3 refugee camps in Kupang regency

Method: This study used a mixed method for 81 eligible women. Data were collected by questionnaire and in-depth interview. Data was analysed univariately and explanatively.

Results and Discussion: This study found that $80.2 \%$ of women in their early teens at the time of their first pregnancy and $53.1 \%$ of eligible women who did not use contraception. Meanwhile, only $43.2 \%$ of pregnant women regularly did the Antenatal care (ANC), and only $37 \%$ of mothers did exclusive breastfeeding. The qualitative findings found 3 main themes; 1) Teenage pregnancy; 2) Pregnancy control; 3) Barriers in accessing reproductive service Conclusion: Overall, teenage pregnancy has been a serious problem for refugee women, and it has been aggravated by the low awareness to use contraception and to do ANC. Therefore, the government needs to provide comprehensive, tolerant, and congruent reproductive health services based on culture and complexity of the problems in the refugee camp community.
\end{abstract}

Keywords: Reproductive Health; Women; Refugees; East Timor

\section{ABSTRAK}

Latar Belakang: Problem kemiskinan yang menimpa pengungsi pada prinsipnya turut memperburuk kesehatan reproduksi perempuan pengungsi. Tujuan: Penelitian ini bertujuan untuk memotret permasalahan kesehatan reproduksi perempuan usia subur eks pengungsi Timor Timur di tiga camp pengungsian yang ada di Kabupaten Kupang.

Metode: Penelitian ini menggunakan mixed method pada 81 perempuan usia subur. Data dikumpulkan mengunakan lembar kuesioner dan wawancara mendalam. Data dianalisis secara univariat dan eksplanatori.

Hasil dan Pembahasan: Hasil penelitian menunjukkan bahwa sebanyak $80.2 \%$ perempuan pengungsi melahirkan pertama kali saat berusia remaja awal dan sebanyak 53.1\% perempuan usia subur tidak menggunakan kontrasepsi. Hanya $43.2 \%$ ibu yang teratur melakukan pemeriksaan ANC dan hanya $37 \%$ ibu yang memberikan ASI esklusif. Studi kualitatif menemukan tiga tema utama yaitu: 1) Kehamilan remaja; 2) Kontrol Kehamilan; 3) hambatan dalam mengakses pelayanan reproduksi.

Kesimpulan: Kehamilan remaja masih menjadi permasalahan serius bagi perempuan pengungsi dan diperburuk dengan rendahnya kesadaran untuk mengunakan kontrasepsi dan pemanfaatan ANC. Oleh karena itu pemerintah perlu menyediakan layanan kesehatan reproduksi yang komprehensif, toleran, serta kongruen secara budaya sesuai dengan kompleksitas permasalahan di komunitas pengungsi.

Kata kunci: Kesehatan Reproduksi; Perempuan; Pengungsi; Timor Timur 


\section{PENDAHULUAN}

Sejarah pengungsi Timor Timur di NTT di mulai sejak jajak pendapat 1999, jumlah korban kekerasan yang tercerabut dari kampung halaman sebanyak 450.000, dimana 240.000 adalah pengungsi lintas batas (refugees) yang diungsikan ke Timor bagian barat, dan 210.000 mengalami ekslusi di dalam wilayah Timor- Timur, yang disebut IDP (Internally Displaced Person) lain. ${ }^{1,2}$

Berdasarkan data dari pemerintah kabupaten Kupang terdapat 3769 kepala keluarga (KK) eks pengungsi Timor-Timur yang telah menjadi warga baru tersebar di 34 desa di kabupaten Kupang. Meskipun telah 18 tahun mengungsi ke wilayah Timur Barat masih terdapat sebagian besar KK yang mendiami camp-camp penampungan yang tidak layak huni milik TNI AD karena ketiadaan lahan tempat tinggal. ${ }^{2,3}$ Hasil pengumpulan data awal, di Desa Noelbaki didapatkan bahwa kurang lebih 384 Kepala Keluarga (KK) eks pengungsi Timor Timur yang mendiami 3 camp penampungan pengungsi. Permasalahan yang timbul sebagai dampak dari status pengungsi adalah kemiskinan akibat hilangnya mata pencaharian serta diskriminasi yang berdampak pada hambatan dalam mengakses layanan vital. ${ }^{3}$

Pengungsi perempuan dan anak-anak merupakan kelompok yang sangat rentan akibat kemiskinan dan diskriminasi. Beragam permasalahan kesehatan yang dialami oleh perempuan sebagai dampak dari statusnya sebagai pengungsi meliputi 1) Pengaturan kesuburan (kontrasepsi), 2) penyakit menular seksual, 3) kekerasan berbasis seks dan gender, 4) kehamilan dan persalinan, serta 5) ketersediaan dan pemanfaatan fasilitas kesehatan. ${ }^{4}$

Berbagai permasalahan kesehatan reproduksi pengungsi tersebut akan memberikan dampak yang cukup serius terhadap status demografi negara, karena kesehatan reproduksi yang baik akan mempengaruhi kualitas demografi manusia. Penelitian ini bertujuan untuk memberikan gambaran mengenai status kesehatan reproduksi perempuan eks pengungsi Timor-Timur di camp Pengungsi Noelbaki. Hasil penelitian ini dapat dipakai sebagai basis data dan informasi bagi pemerintah dalam memformulasikan kebijakan untuk pengungsi TimorTimur, serta bagi pihak swasta dalam mengadvokasi pengungsi meraih kehidupan yang lebih baik.

\section{METODE}

Penelitian ini menggunakan metode campuran kuantitatif dan kualitatif (mixed method) dengan strategi eksplanatoris sekuensial yaitu peneliti melakukan pengumpulan dan analisis data kuantitatif pada tahap pertama diikuti dengan pengumpulan data dan analisis data pada tahap kedua yang dibangun berdasarkan hasil awal kuantitatif. Peneliti menggunakan metode penelitian integrative ini agar dapat memperoleh pemahaman yang lebih mendalam terkait pemasalahan kesehatan reproduksi perempuan eks pengungsi.

Rancangan penelitian kuantitatif yang digunakan adalah survey lintas bagian (cross-sectional survey) yaitu mengumpulkan data satu persatu dalam satu waktu. Metode ini dipilih karena dapat mengidentifikasi sifat-sifat suatu populasi berdasarkan sekelompok kecil individu (sampel). Setelah menggumpulkan data dengan menggunakan survey, peneliti melakukan pengumpulan data secara kualitatif dengan pendekatan fenomenologi untuk mengeksplorasi permasalahan kesehatan reproduksi perempuan eks pengungsi Timor Timur.

Penelitian ini terbagi atas 3 tahapan meliputi: Tahap pertama mengumpulkan data primer terkait data sosiodemografi dan data status kesehatan reproduksi yang meliputi: umur, status perkawinan, pendidikan, status pekerjaan, status sosial ekonomi, riwayat obstetrik (riwayat kehamilan, persalinan, dan nifas). Tahapan kedua adalah melakukan wawancara mendalam (in-depth interview) untuk menggali permasalahan kesehatan reproduksi yang dialami oleh pengungsi perempuan. Subjek wawancara adalah pengungsi perempuan sebagai informan inti dan tenaga kesehatan serta anggota keluarga yang tinggal serumah (suami/orangtua/ mertua) sebagai informan pendukung. Tahap Ketiga: menyusun laporan penelitian.

Lokasipenelitianiniadalah 3camppenampungan pengungsi di desa Noelbaki Kabupaten Kupang yaitu Camp Balai Benih Induk (BBI) dengan jumlah 217 KK, Camp Terminal sejumlah 117 KK, Camp Pabrik Kulit dengan jumlah 14 KK. Sampel penelitian ini adalah semua perempuan usia subur eks pengungsi Timur-Timur yang tinggal di camp penampungan pengungsi dengan kriteria inklusi sebagai berikut: (1) Perempuan Usia Subur (PUS) yang memiliki 
pasangan; (2) Bersedia menjadi reponden. Kriteria esklusi dalam penelitian ini adalah perempuan yang memiliki gangguan mental kronik. Teknik sampling yang digunakan adalah total sampling untuk pendekatan kuantitatif dan purposive sampling untuk kajian kualitatif. Jumlah sampel dalam penelitian ini adalah 81 Wanita Usia Subur (WUS) yang terdiri dari camp BBI 45 responden; Camp Terminal Noelbaki : 31 responden, dan Camp Pabrik Kulit: 5 responden. Saturasi data kualitatif tercapai pada informan ke-7 (tujuh). Peneliti kemudian melakukan triangulasi sumber untuk mempertahankan keabsahan data penelitian.

Instrumen pengumpulan data yang digunakan adalah kuesioner, panduan wawancara, alat perekam dan alat tulis. Data kuantitatif di analisis menggunakan analisis univariat, sedangkan hasil transkrip wawancara dianalisis menggunakan analisis eksplanatori.

\section{HASIL DAN PEMBAHASAN}

\section{Hasil analisis Kuantitatif}

Berikut ini dipaparkan hasil analisis univariat yang meliputi karakteristik responden dan gambaran permasalahan kesehatan reproduksi pada 81 perempuan eks pengungsi Timor Timur.

\section{a. Karakteristik repronden}

Tabel 1 menggambarkan karakteristik dari 81 repsonden yang terdiri atas usia, agama, status pernikahan, tingkat pendidikan, pekerjaan, serta pendapatan keluarga.

Tabel 1.Karakteristik responden

\begin{tabular}{|c|c|c|c|}
\hline No & Variabel & Frekuensi & Persentase (\%) \\
\hline \multirow[t]{5}{*}{1} & Usia & & \\
\hline & Remaja akhir & 22 & 27.2 \\
\hline & Dewasa awal & 42 & 42 \\
\hline & Dewasa akhir & 15 & 15 \\
\hline & Lansia awal & 2 & 2 \\
\hline \multirow[t]{4}{*}{2} & Agama & & \\
\hline & Katolik & 62 & 76.5 \\
\hline & Protestan & 10 & 12.3 \\
\hline & Islam & 9 & 11.1 \\
\hline \multirow[t]{4}{*}{3} & Status pernikahan & & \\
\hline & Menikah & 59 & 72.8 \\
\hline & Belum Menikah & 20 & 24.7 \\
\hline & Cerai & 2 & 2.5 \\
\hline \multirow[t]{6}{*}{4} & Tingkat pendidikan & & \\
\hline & Tidak sekolah & 14 & 17.3 \\
\hline & SD & 19 & 23.5 \\
\hline & SMP & 17 & 21.0 \\
\hline & SMA & 28 & 34.6 \\
\hline & Sarjana & 3 & 3.7 \\
\hline \multirow[t]{5}{*}{5} & Pekerjaan & & \\
\hline & IRT & 72 & 88.9 \\
\hline & Buruh & 3 & 3.7 \\
\hline & Swasta & 5 & 6.2 \\
\hline & Honorer & 1 & 1.2 \\
\hline \multirow[t]{4}{*}{6} & Pendapatankeluarga & & \\
\hline & $\leq \mathrm{UMK}$ & 64 & 79 \\
\hline & $>$ UMK & 17 & 2 \\
\hline & Total & 81 & 100 \\
\hline
\end{tabular}

Sumber: Data primer 
Karakteristik reponden dalam penelitian ini sebagian besar (42\%) berusia dewasa awal dan beragama katolik (76.5\%). Tingkat pendidikan responden terbanyak adalah SMA (34.65\%) dan sebagian besar (88.9\%) tidak bekerja dan sebagian besar pendapatan keluarga masih di bawah UMK (79\%).

\section{b. Hasil analisis univariat}

Tabel 2 menggambarkan status kesehatan reproduksi dari 81 repsonden perempuan eks pengungsi Timor Timur.

Tabel 2. Usia pertama kali mempunyai anak, jumlah anak, pengunaan KB, serta riwayat pemanfaatan ANC dan riwayat ASI esklusif

\begin{tabular}{|c|c|c|c|}
\hline No & Variabel & Frekuensi & Persentase (\%) \\
\hline \multirow[t]{4}{*}{1} & Usia pertama kali mempunyaianak & & \\
\hline & Remaja awal & 7 & 8.6 \\
\hline & Remaja akhir & 65 & 80.2 \\
\hline & Dewasa awal & 9 & 10.2 \\
\hline \multirow[t]{3}{*}{2} & Jumlah anak & & \\
\hline & $\leq 2$ & 36 & 44.6 \\
\hline & $>2$ & 45 & 56.4 \\
\hline \multirow[t]{3}{*}{3} & KB & & \\
\hline & Tidak menggunakan KB & 43 & 53.1 \\
\hline & Menggunakan KB & 38 & 46.9 \\
\hline \multirow[t]{2}{*}{4} & Riwayat ASI esklusif & 51 & 63 \\
\hline & $\begin{array}{l}\text { Tidak memberikan ASI eksklusif } \\
\text { Memberikan ASI eksklusif }\end{array}$ & 30 & 37 \\
\hline \multirow[t]{4}{*}{5} & Riwayat pemanfaatan ANC & & \\
\hline & Tidak teratur & 46 & 56.8 \\
\hline & Teratur & 35 & 43.2 \\
\hline & Total & 81 & 100 \\
\hline
\end{tabular}

Sumber: Data primer

Berdasarkan tabel 2 dapat disimpulkan bahwa sebagian besar responden (80.2\%) pertama kali mempunyai anak pada usia remaja akhir. Sebagian besar reponden (53.1\%) tidak menggunakan KB dan sebagian besar repsonden (56.4\%) mempunyai anak lebih dari dua orang. Hasil penelitian juga menemukan bahwa $55 \%$ reponden memiliki riwayat tidak aktif mengikuti Antenatal Care (ANC) dan 59\% memiliki riwayat tidak memberikan ASI eksklusif.

Temuan utama dalam penelitian kuantitatif adalah primimuda dan rendahnya penggunaan kontrasepsi.Kedua hal ini berdampak pada tingginya angka fertilisasi pada pengungsi. Hal ini sejalan dengan hasil penelitian sebelumnya bahwa migrasi secara paksa dapat meningkatkan fertilisasi, karena adanya dorongan dari pengungsi untuk 'repopulasi', atau mengisi kembali dan menggantikan jumlahnya yang hilang atau berkurang. Peningkatan jumlah penduduk pengungsi semakin diperburuk dengan ketetidaktersediaan kontrasepsi dan kurangnya pengetahuan terkait pemanfaatan kontrasepsi ${ }^{4-6}$

Temuan lainnya adalah rendahnya pemanfaatan pelayanan ANC. Masalah kesehatan selama masa kehamilan, persalinan, dan pascapersalinan juga menjadi permasalahan yang dialami perempuan pengungsi, hal tersebut dikaitkan dengan kemiskinan yang berdampak pada status nutrisi dan hambatan dalam mengakses pelayanan kesehatan yang adekuat akibat perbedaan bahasa dan budaya antara perempuan pengungsi dan petugas kesehatan. ${ }^{4-6}$

\section{Hasil analisis kualitatif}

Hasil temuan kualitatif dirumuskan dalam 3 tema penelitian meliputi (1) kehamilan remaja, 
(2) Kontrol kehamilan, serta (3) Hambatan dalam mengakses pelayanan kesehatan

\section{a. Kehamilan remaja}

Kehamilan remaja meningkat di kalangan remaja perempuan eks pengungsi. Terdapat dua penyebab kehamilan remaja di kalangan perempuan pengungsi yaitu kehamilan diluar nikah dan keputusan untuk menikah di usia muda. Kehamilan di luar nikah menyumbang $60 \%$ kehamilan remaja di kalangan perempuan eks pengungsi Timor Timur di Timor Barat. Walaupun seks pranikah dan kehamilan di luar nikah tidak disetujui dan tidak ditoleransi oleh masyarakat di lingkungan pengungsi namun kontrol yang rendah dari orangtua menyebabkan banyak remaja jatuh dalam pergaulan bebas yang berdampak pada kehamilan di luar nikah.

"Anak-anak di sini banyak yang hamil bahkan sebelum selesai sekolah. Mungkin karena kegiatan remaja di sini kurang makanya seperti itu" (Tn A, 40 tahun, Koordinator pengungsi).

Penyebab kedua tingginya angka kehamilan remaja adalah keputusan untuk menikah di usia muda. Berdasarkan hasil wawancara, beberapa reponden memilih untuk menikah di usia remaja karena menjadi ibu rumah tangga adalah pilihan karir satu-satunya setelah kemungkinan untuk sekolah sudah tertutup sebagai dampak dari kemiskinan.

"Saya tidak mungkin bisa sekolah, jadi sebaiknya saya menikah saja karena kebetulan pacar saya sudah menawarkan pernikahan (Ny Y, 21Tahun).

Pernikahan menjadi strategi bagi perempuan pengungsi untuk keluar dari lingkungan rumah yang miskin dan mencari kehidupan yang lebih baik. Melalui pernikahan seluruh kebutuhan perempuan akan menjadi tanggungjawab suaminya setelah pernikahan. Akan tetapi berdasarkan hasil penelitian yang di sebelumnya, perempuan pengungsi yang telah menikah tetap ikut andil dalam membantu perekonomian keluarga. Rata-rata perempuan pengungsi bekerja menjadi buruh pemetik sayur dengan upah rata-rata per hari Rp. 5000 - Rp. 8000 dengan waktu kerja selama 8 jam per hari. Upah yang diterima oleh para perempuan ini digunakan untuk kegiatan konsumtif. ${ }^{3}$
Terlepas dari alasan apapun, kehamilan remaja tetap memberikan dampak negatif bagi remaja. Reproduksi sehat untuk hamil dan melahirkan berkisar antara usia 20-30 tahun. Jika terjadi kehamilan di bawah atau di atas usia tersebut akan berisiko terjadinya kematian 2 hingga 4 kali lebih tinggi dari reproduksi sehat. Hingga saat ini, berbagai kajian internasional telah menetapkan bahwa kehamilan remaja membawa kerugian bagi kesehatan, kesejahteraan mental dan psikologi remaja. Kehamilan remaja dapat menghambat peluang karir dan peningkatan ekonomi, meningkatkan kemiskinan serta menghambat prospek masa depan remaja. Beberapa dampak negatif kehamilan pada usia remaja bagi kesehatan adalah anemia, hipertensi gestasional, preeklamsia, prematuritas dan berat badan lahir rendah. ${ }^{7}$ Cambodia, Indonesia, Papua New Guinea, Philippines, Solomon Islands, Timor-Leste, Vanuatu, and Vietnam were reviewed. Data on 128 indicators, including ARH outcomes, outcomes for babies of adolescent mothers, and adolescents' access to health information and services, were mapped. Available data are limited because of the omission of cohorts such as young adolescents (10-14 years old

Menilik tingginya angka kehamilan remaja, perlu perhatian khusus pemerintah untuk mencegah kehamilan remaja dan mencegah kehamilan berulang pada ibu remaja (Repeat pregnancy in adolescents). Selain itu, model pelayanan kesehatan yang diperlukan adalah konsep youth friendly. Konsep ini merujuk pada sikap petugas yang ramah, penuh perhatian dan tidak menggurui dalam memberikan pelayanan sehingga dapat mengatasi hambatan pemanfaatan pelayanan kesehatan remaja. Intervensi psikososial (KIE terkait kesehatan reproduksi), kunjungan rumah dan pendampingan keluarga muda, serta penguatan pogram keluarga berencana juga perlu untuk mencegah kehamilan berulang pada ibu remaja. ${ }^{8,9}$

\section{b. Kontrol kehamilan}

Pernikahan usia remaja menyebabkan masa reproduksi seorang perempuan menjadi lebih panjang. Apabila tidak di kontrol maka akan berdampak pada tingginya angka kelahiran. Hal 
ini merupakan mata rantai yang harus diputuskan untuk mencegah lonjakan penduduk. Berdasarkan temuan kuantitatif sebagian besar WUS (53.1\%) tidak mengikuti program keluarga berencana. Pengetahuan dan keyakinan tentang kontrasepsi mempengaruhi motivasi dan keputusan untuk menggunakan kontrasepsi. Hasil wawancara menunjukkan bahwa pemahaman WUS tentang kontrasepsi masih rendah. Informan masih takut akan efek samping kontrasepsi terhadap kesehatan. Informan berasumsi bahwa kontrasepsi dapat menyebabkan gangguan kesehatan seperti keganasan, peningkatan berat badan, gangguan siklus menstruasi. Asumsi tersebut dibangun berdasarkan pengalaman anggota keluarga yang mengalami hal tersebut.

"Saya tidak pakai KB, saya takut seperti saya punya tanta kena kanker rahim karena pakai Implan" ( Ny.A,24 tahun)

Temuan lain menunjukkan bahwa ada hambatan mengenai penggunaan kontrasepsi oleh perempuan eks pengungsi Timor-Timur, yang terkait langsung dengan budaya mereka. Menjadi seorang 'ibu" adalah suatu persyaratan sosial. Perempuan mempunyai kewajiban menjaga kelangsungan keturunan. Keluarga biasanya melarang menggunakan kontrasepsi karena dianggap membatasi keturunan.

Perempuan membutuhkan persetujuan suami dan mertua untuk menggunakan kontrasepsi. Hal tersebut menjadi salah satu penyebab ibu tidak menggunakan kontrasepsi.

"Saya mau pakai KB, tapi suami dan orangtua bilang harus tambahan anak lagi, kadang saya jadi dilema tapi takut mau jujur ke bidan "(Ny Y, 29 tahun)

Perempuan mempunyai hak untuk memutuskan apakah ingin mempunyai anak dan kapan mempunyai anak. Hak tersebut merupakan hak asasi manusia yang di dukung oleh badan kesehatan dunia (WHO). ${ }^{10-11}$ Perempuan harus diberikan akses informasi seluas-luasnya mengenai metode kontrasepsi, dan diberikan kebebasan untuk memilih kontrasepsi tanpa paksaan, diskriminasi, atau kekerasan. Kontrasepsi memfasilitasi kemampuan perempuan untuk membatasi jumlah anak, mengurangi morbiditas dan mortalitas yang terkait pemasalahan kesehatan reproduksi, dan memungkinkan perempuan untuk menyelesaikan pendidikan yang dapat meningkatkan status ekonomi perempuan dan keluarga. ${ }^{12}$

Berdasarkan uraian tersebut, keputusan menggunakan kontrasepsi sangat penting bagi perempuan karena merupakan hak asasi perempuan dan berdampak pada status kesehatan dan kualitas hidup perempuan tidak terkecuali perempuan eks pengungsi Timor-Timur. Rendahnya angka pengguna kontrasepsi pada WUS disebabkan oleh pengaruh keluarga, budaya atau agama, dan pengalaman dengan berbagai metode hormonal.

Berdasarkan hasil penelitian sebelumnya menemukan bahwa keluarga dirujuk sebagai elemen yang mempengaruhi dalam keputusan tentang kesehatan reproduksi. Keluarga disini merujuk pada suami dan atau mertua. ${ }^{13}$ Temuan dalam penelitian ini menggambarkan bahwa suami atau mertua yang memberikan keputusan dalam penggunaan kontrasepsi. Budaya patriarkhi di kalangan pengungsi menyebabkan kontrol dan pusat kekuasaan ada pada suami. Sejumlah perempuan menggambarkan suami mereka memiliki wewenang untuk memutuskan kapan, dan berapa banyak anak yang akan dimiliki.

Tradisi budaya dan kepercayaan agama juga diidentifikasi sebagai faktor utama yang memengaruhi keputusan reproduksi. "keibuan" merupakan pusat identitas di seluruh kelompok budaya timur. Agama dan budaya menekankan pentingnya identitas "ibu" seorang perempuan. Pengakuan akan identitas "ibu" akan diterima seorang perempuan jika sudah memiliki anak. Dampak sosial dari infertilitas adalah pengasingan, pengucilan, dan pelecehan, dan kekerasan. Tidak hanya harus memiliki anak untuk mendapatkan pengakuan identitas "ibu", perempuan juga dihadapkan pada kewajiban untuk memberikan keturunan laki-laki bagi keluarga. Sebagai konsekuensi dari persyaratan ini, banyak perempuan melaporkan bahwa mereka merasa ditekan untuk terus hamil sampai mereka memiliki anak laki-laki. ${ }^{14}$

Selain itu pengalaman pribadi maupun pengalaman kelompoknya tentang metode keluarga berencana juga mempengaruhi pilihan metode kontrasepsi. Wanita yang memiliki pengalaman terkait efek samping ataupun pengalaman keluarga (ibu, tanta, atau mertua) terkait efek samping 
kontrasepsi menjadi rujukan dalam membuat keputusan menggunakan kontrasepsi. Beberapa repsonden mengungkapkan tentang perdarahan berlebihan, ketakutan akan penyakit dan keganasan atau kanker, peningkatan berat badan sebagai efek buruk dari kontrasepsi. ${ }^{6}$

Petugas kesehatan perlu menyediakan informasi yang akurat mengenai kontrasepsi sesuai kebutuhan pengungsi untuk meningkatkan pemahaman pengungsi tentang kontrasepsi. Kegiatan Komunikasi Informasi dan Edukasi (KIE) harus sesuai dengan kebutuhan dan permasalahan wanita pengungsi serta pola pendekatan yang digunakan harus tepat sesuai dengan kompleksitas permasalahaan di lingkungan pengungsi.

Pendekatan kolaboratif dapat digunakan untuk menjembatani perempuan dan keluarga sebagai pengambil keputusan. Petugas kesehatan perlu mengidentifikasi siapa yang menjadi pengambil keputusan dan menghadirkan suami saat memberikan konseling keluarga berencana serta memberikan kesempatan untuk pengambilan keputusan secara bersama. ${ }^{6}$

\section{c. Hambatan dalam mengakses pelayanan kesehatan}

Hasil survey menunjukan bahwa riwayat kunjungan ANC masih rendah. Hal tersebut dikuti dengan rendahnya kunjungan posyandu. Pelayanan posyandu di 3 camp pengungsi terbagi dalam dua wilayah pelayanan yaitu posyandu Balai Benih Induk (BBI) dan posyandu Terminal Noelbaki .Posyandu BBI melayani semua WUS dan balita yang tinggal di camp pengungsi BBI. Kader posyandunya adalah sesama perempuan pengungsi yang tinggal di camp tersebut. Sedangkan posyandu di terminal Noelbaki tidak lagi aktif sehingga kegiatan posyandu digabung dengan warga lokal. Kader posyandu di terminal Noelbaki berasal dari warga lokal. Hasil kajian peneliti, ditemukan bahwa tingkat partisipasi dan keaktifan perempuan pengungsi di kedua posyandu ini berbeda. Tingkat partisipasi perempuan eks pengungsi di posyandu BBI lebih tinggi dibandingkan pada posyandu Terminal Noelbaki.

Berdasarkan hasil wawancara terhadap kader posyandu Noelbaki menunjukkan tingkat partisipasi perempuan eks pengungsi rendah dalam kegiatan posyandu walaupun telah diinformasikan jadwal kegiatan posyandu. Para ibu menghadiri kegiatan posyandu jika ada pembagian makanan tambahan berupa biskuitatau susu formula dari pihak puskemas. Perempuan pengungsi selalu digambarkan dengan "susah diatur", "malas" dan "mempunyai tingkat pemahaman rendah". Hal tersebut mempengaruhi pelayanan terhadap perempuan eks pengungsi. Sebaliknya ketika dikonfirmasi kepada responden pengungsi, mereka menyadari pentingnya kegiatan ANC dan posyandu akan tetapi masih ada perasaan berbeda dalam pelayanan yang diterima sehingga menjadikan mereka enggan untuk mengikuti kegiatan tersebut. Berbeda dengan posyandu BBI, tingkat partisipasinya menjadi tinggi karena dilayani oleh sesama perempuan dari komunitas mereka sehingga mereka merasa lebih aman.

Para pengungsi seringkali mengabaikan kesehatan fisik dan mental mereka, karena disibukkan oleh kekhawatiran tentang status tempat tinggal, posisi yang tidak jelas dan rasa tidak aman dalam masyarakat, ditambah pengalaman terhadap stigma warga lokal. Hal tersebut memicu rasa tidak percaya pada orang lain. Permasalahan menjadi semakin kompleks ketika praktisi kesehatan tidak diberikan pelatihan dan pemahaman untuk memberikan pelayanan kesehatan bagi para pengungsi yang memiliki pengalaman, harapan dan kebutuhan yang berbeda dengan warga lokal. Praktisi kesehatan juga tidak siap untuk memberikan layanan kepada kelompok populasi pengungsi dengan kebutuhan yang sedemikian kompleks. Akibatnya pelayanan kesehatan reproduksi yang tersedia belum secara khusus menjangkau perempuan pengungsi. 15,16

\section{KESIMPULAN DAN SARAN}

Berdasarkan hasil penelitian disimpulkan bahwa pemasalahan kesehatan reproduksi pada perempuan usia subur meliputi tingginya WUS usia remaja, rendahnya tingkat partisipasi penggunaan KB sehingga meningkatnya fertilisasi. Kehamilan remaja masih menjadi permasalahan utama di kalangan remaja pengungsi. Seks bebas dan keputusan menikah di usia muda menjadi alasan utama tingginya kehamilan remaja. Hal ini diperburuk dengan benturan budaya dan kesadaran 
menggunakan kotrasepsi yang masih rendah. Penelitian ini juga menemukan bahwa riwayat kunjungan ANC dan riwayat pemberian ASI esklusif masih rendah di kalangan perempuan pengungsi. Hambatan utama dalam pemanfaatan ANC adalah komunikasi dan stigmatisasi dari petugas kesehatan terhadap pengungsi.

Kompleksitas permasalahan kesehatan reproduksi yang disajikan dalam penelitian ini dapat dimanfaatkan untuk mengidentifikasi dan mengembangkan strategi yang efektif terkait penyediaan layanan kesehatan seksual dan reproduksi yang komprehensif bagi komunitas perempuan pengungsi di tiga camp tersebut. Oleh karena itu penulis memberikan rekomendasi sebagai berikut: 1) Mengembangkan dan menyediakan pelayanan kesehatan reproduksi yang komperensif dan kongruen secara budaya termasuk perawatan prenatal dan keluarga berencana; 2) Mengadvokasi lingkungan yang toleran untuk mengurangi stigmatisasi di komunitas pengungsi.

\section{DAFTAR PUSTAKA}

1. Janowski Kris. East Timorese Refugee Saga Comes to an End. 2002; Available from: https://www. unhcr.org/news/latest/2002/12/3e1060c84/easttimorese-refugee-saga-comes-end.html

2. Dhosa DD. Ekonomi Politik dan Pembangunan Eks Pengungsi Timor Timur. Pos Kupang. 2016;

3. Dhosa, DD dan Ratumakin P. Ekonomi politik redistribusi tanah, dinamika kelas dan perjuangan pengungsi timor timur di timor barat indonesia. J Pendidik dan Kebud Missio. 2019;11(1).

4. Gagnon AJ, Merry L, Robinson C. A Systematic Review of Refugee Women's Reproductive Health. Refuge. 2002;21(1):6-17.

5. Barnes DM, Harrison CL. Refugee women's reproductive health in early resettlement. JOGNN J Obstet Gynecol Neonatal Nurs. 2004;33(6):723-8.

6. Agbemenu K. Reproductive Health Decision Making among U.S. dwelling Somali Bantu Refugee Women: A Qualitative Study. J cllinical Nurs. 2016;38(1):42-9.
7. Gray N, Azzopardi P, Kennedy E, Willersdorf E, Creati $M$. Improving adolescent reproductive health in Asia and the Pacific: Do we have the data? A review of DHS and MICS surveys in nine countries. Asia-Pacific J Public Heal. 2013;25(2):134-44.

8. Whitaker R, Hendry M, Aslam R, Booth A, Carter $B$, Charles JM, et al. Intervention now to eliminate repeat unintended pregnancy in teenagers (INTERUPT): A systematic review of intervention effectiveness and cost-effectiveness, and qualitative and realist synthesis of implementation factors and user engagement. Health Technol Assess (Rockv). 2016;20(16):1-214.

9. Yani VD, Emilia O, Kusnanto H. Persepsi Remaja Terhadap Faktor Penghambat. Persepsi Remaja Terhadap Fakt Penghambat Pemanfaat Pelayanan Kesehat Reproduksi Di Puskesmas Gamb Kabupaten Sijujung [Internet]. 2014;1(1):34-45. Available from: https://jurnal.ugm.ac.id

10. UNFPA. Choices not Chance- UNFPA Family Planning Strategy 2012-2020. In: Unfpa. 2012. p. 1-4.

11. World Health Organization. Contraception fact sheet. 2014;

12. World Health Organization. Ensuring human rights within contraceptive programmes. 2014. 50 p.

13. Meo MLN. Persepsi ibu terkait pemanfaatan pelayanan ANC di Kota Kupang. 2019;9(2):79-86. Available from: https://ejournal2.litbang.kemkes. go.id/index.php/kespro/article/view/935/1119

14. Hawkey AJ, Ussher JM, Perz J. "If You Don't Have a Baby, You Can't Be in Our Culture": Migrant and Refugee Women's Experiences and Constructions of Fertility and Fertility Control. Women's Reprod Heal. 2018;5(2):75-98.

15. Janssens K, Bosmans $\mathrm{M}$, Leye $\mathrm{E}$, Temmerman $\mathrm{M}$. Sexual and reproductive health of asylum-seeking and refugee women in europe: Entitlements and access to health services. J Glob Ethics. 2006;2(2):183-96.

16. Drummond PD, Mizan A, Brocx K. Health Care for Women International Barriers to Accessing Health Care Services for West African Refugee Women Living in Western Australia Barriers to Accessing Health Care Services for West African Refugee Women Living in Western Australia. Health Care Women Int. 2011;32:37-41. 